J. Cent. South Univ. (2015) 22: 1166

DOI: $10.1007 / \mathrm{s} 11771-015-2629-0$

\title{
Erratum to: Coefficient of consolidation by end of arc method
}

\author{
Mohsen Abbaspour ${ }^{1}$, Reza Porhoseini ${ }^{1}$, Kazem Barkhordari ${ }^{1}$, Ahmad Ghorbani $^{2}$ \\ 1. School of Technical \& Engineering, Department of Civil Engineering, Yazd University, \\ University Blvd, Safayieh, Yazd, Iran; \\ 2. School of Mining and Metallurgy, Department of Mine Exploration, Yazd University, \\ University Blvd, Safayieh, Yazd, Iran \\ (C) Central South University Press and Springer-Verlag Berlin Heidelberg 2015
}

Erratum to: J. Cent. South Univ. (2015) 22: 332-337

DOI: $10.1007 / \mathrm{s} 11771-015-2526-6$

The original version of this article unfortunately contained two mistakes. The mistakes are corrected as follows:

1) The spelling of the first author is incorrect. The correct name is Mohsen Abbaspour.

2) The datum of the third row and the third line in Table 3 should be 1950. 